\title{
Characteristic Analysis of Ecological Water Use in Xilin River Basin Based on Remote Sensing
}

\author{
Hongbo Yu ${ }^{1}$, Jie Chen ${ }^{2, *}$, Qiaofeng Zhang ${ }^{1}$ \\ 1. College of Geograghy Science, Inner Mongolia Normal University, Huhhot 010022, China \\ 2. Inner Mongolia Radio and TV Station, Huhhot 010058, China
}

Received October 27, 2018

Accepted November 15, 2018

\begin{abstract}
Our study area is the Xilin River basin. Remote sensing approach was used to retrieve ecological water use by using MODIS images from Apr. to Sept. of 2000、2007、2010-2014, and using auxiliary environmental data from the same time periods. The results showed the spatial distribution of ecological water use was consistent with the land surface condition. The ecological water use had the trend of strip reduction from the upstream to the middle and lower reaches. The annual variation was extremely related to the precipitation. Large amount of precipitation in the year, ecological water use was larger, and vice versa. The areas with higher ecological water use were forest land and farmland, followed by unutilized land. Grassland and construction land were lower. The order of ecological water use of different land use type was basically: forest land $>$ farmland $>$ unutilized land $>$ construction land > grassland. In the year of abundant water, the time of the maximum value of ecological water use appeared in June-July with the time of precipitation. In dry year, the time of the maximum value had no rule. The single factor correlation analysis of the monthly ecological water use and monthly meteorological factors showed that the most relevant meteorological factor is precipitation. The correlation coefficient is 0.776 .
\end{abstract}

Keywords: Xilin River basin, ecological water use, remote sensing, land use

\section{基于遥感的锡林河流域生态用水特征分析}

\author{
于红博 ${ }^{1}$, 陈 杰 $^{2, *}$, 张巧风 ${ }^{1}$ \\ 1. 内蒙古师范大学地理科学学院, 呼和浩特 010022 \\ 2. 内蒙古广播电视台, 呼和浩特 010058
}

\begin{abstract}
摘 要: 本研究选择锡林河流域为研究区，利用遥感方法对2000年、2007年、2010年-2014年每年4-9月的 MODIS影像数据进行处理, 结合同期气象资料以及实测数据估算流域生长季生态用水量。结果表明, 流域 生态用水量空间分布与地表状况比较吻合, 生态用水量基本均为由上游到中下游呈条带状减少的趋势, 年 际变化与降水量极为相关, 降水量大的年份, 生态用水量大, 生态用水量大的区域所占面积越大, 包括流 域大部分区域, 反之亦然。生态用水较高的地类为林地和耕地, 其次为未利用地, 草地和建设用地生态用 水较低, 基本为林地>耕地>未利用地>建设用地>草地。在降水充沛的年份, 生态用水最大值主要出现在雨 量充沛的6-7月份, 在降水欠缺的年份, 最大值出现的时间没有规律。将月生态用水量与月气象数据进行了 单因子相关分析，表明降水是影响生态用水量大小的主要限制因子，相关系数为 0.776 。
\end{abstract}

关键词：锡林河流域; 生态用水; 遥感; 土地利用

*通讯作者: $1106275721 @ q q . c o m$

Copyright (C) 2019, the Authors. Published by Atlantis Press.

This is an open access article under the CC BY-NC license (http://creativecommons.org/licenses/by-nc/4.0/). 


\section{1 引言}

锡林河流域位于内蒙古高原中东部, 在内 蒙古锡林郭勒盟和赤峰市克什克腾旗境内, 东 缘属于大兴安岭西麓低山丘陵区。该流域内的 天然草地是内蒙古高原的典型代表, 是京津冀 等地区重要的绿色屏障, 该流域拥有目前我国 最大的草原与草甸生态系统类型的自然保护 区, 对草原生物多样性保护起到重要作用, 在 全球变化动态监测等方面占有重要的空间位 置和明显的国际影响 ${ }^{[1]}$ 。该流域属于干旱半干 旱地区, 降水量小, 蒸散量大, 水量收支不平 衡。特别是近年来, 煤矿开采频繁, 城镇化发 展迅速, 工业用水增加, 人类在将水资源的使 用权优先地赋予给灌溉农业、工业和居民生活 的同时, 挤占和剥夺了生态系统用水, 水资源 供需矛盾十分严峻。如何保护生态环境和合理 配置水资源是一个备受关注并需亟待解决的 问题, 生态用水研究受到了专家和学者的广泛 关注 $^{[2-5]}$ 。

“生态用水”一词由汤奇成于 1989 年提 出, 随着人们对生态环境的日益重视, 生态用 水问题已引起越来越广泛的关注, 成为各级领 导、专家学者讨论和研究的热点。“生态用 水” 其内涵宽泛, 尚未有明确统一的定义。许 多研究者根据不同的理解, 对生态用水概念作 出多种不同的界定, 其中将蒸散量看作是生态 用水占有相当比例。宋炳煜先生于 2003 年指 出生态用水是维持各类生态系统正常发育与 相对稳定所必需消耗和现存的水分, 认为草原 植被的生态用水量主要体现在维持草原植被 正常发育与相对稳定所消耗(植物蒸腾和土壤 蒸发)的水和在现状环境条件下土壤所咜存的 水量, 因此其数量等于植物蒸腾量以及土壤蒸 发量 (即植被蒸散量) 与土壤咜水量之和 ${ }^{[6]}$, 本研究采用了该观点。

本研究选择锡林河流域为研究区, 运用遥 感方法, 结合气象资料和实测数据, 对 2000

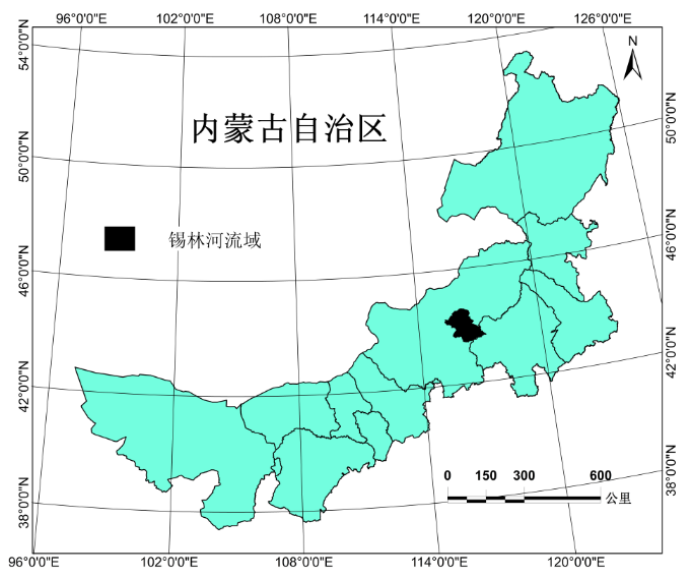

图 1 锡林河流域空间位置图

Fig.1. Spatial location map of Xilin River Basin
年、2007 年、2010 年-2014 年每年 4-9 月的 MODIS 影像进行处理, 估算出该流域的生长 季生态用水量, 来探究锡林河流域生态用水量 的时空变化特征、不同土地利用类型生态用水 特性以及自然影响因子。本研究对该流域植被 耗水量和生态用水量有定量的了解, 对科学有 效地利用干旱地区的有限水资源, 为生态环境 发展的可持续性以及水资源的可持续利用具 有重要的现实意义。

\section{2 研究区概况}

锡林河流域地势由东向西逐渐降低, 流域 总面积约 $10786 \mathrm{~km}^{2}$, 总长 $175 \mathrm{~km}$ 。该流域地 貌具有明显的分区性, 锡林河以南为多级玄武 岩台地, 锡林河中下游是以低山丘陵与高平原 相间分布为特征的内蒙古高原的一部分。该区 的土壤具有明显的地带性, 即由东南向西北有 规律地分布着黑钙土、暗栗钙土和淡栗钙土。 气候属大陆性温带半干旱气候, 冬季寒冷干 燥, 夏季温暖湿润, 根据多年气象资料, 锡林 河内从东南向西北降水量逐渐递减, 东南部的 年降水量为 $400 \mathrm{~mm}$ 左右, 西北部为 $250 \mathrm{~mm}$ 左 右, 年平均气温则从东南向西北逐渐增加。

锡林河流域地带性植被的基本类型是草 原(草甸草原、典型草原), 约占植被总面积的 $85 \%$; 锡林河上游地势较高的三级熔岩台地 上, 代表群系为贝加尔针茅(Stipa baicalensis) 草原和线叶菊(Filifoliusibiricum)草原, 中游暗 栗钙土亚带的代表群系为羊草 (Leymus chinensis)草原和大针茅(Stipa grandis)草原, 下 游淡栗钙土亚带的代表群系为克氏针茅 (Stpa krylovii)草原和冷蒿(Artemisia frigida)草原; 在 锡林河流经区域的地段上形成了湿地植被, 此 外, 在锡林河流域还有浑善达克沙地东北端榆 树疏林、灌丛、草本镶嵌分布所形成的沙生植 被 $^{[1][7] 。}$

\section{3 数据来源}

\section{1 气象数据}

由中国气象科学数据共享服务网提供的 2000 年、 2007 年、 2010 年-2014 年每年 3 月 5 日-10月 15 日逐日气象数据, 包括大气相对湿 度、平均气温、实际水气压、 $2 \mathrm{~m}$ 高度处风速、 降水、实际日照时数。气象数据包括研究区锡 林浩特市及周边阿巴嘎旗、克什克腾旗、东乌 珠穆沁旗、西乌珠穆沁旗、化德、多伦县共 7 个站点的站点数据。

以上气象数据均利用 Kriging 方法进行插 值, 得到面数据。 


\section{2 遥感数据}

遥感影像资料为美国 NASA 提供的 2000 年、 2007 年、 2010 年-2014 年每年 3 月 5 日-10 月 15 日锡林河流域 16 天合成 MODIS 卫星数 据, 是经过验证、MODIS 科学组推荐使用的 L3 级产品。包括地表温度产品 MOD11A2, 地 表反射率和太阳天顶角产品 MOD09A1, 地表 窄波段反照率产品 MCD43A3, 植被指数和太 阳天顶角产品 MOD13A1, 版本均为 5.0。经 过处理, 数据分辨率统一至 $500 \mathrm{~m}$, 投影为 Albers Conical Equal Area 。

\section{3 实测数据}

野外实测数据为 2013-2014 年 4-9 月份 $0-0.5 \mathrm{~m}$ 深度土壤含水量数据, 每个样地三次重 复, 取平均值, 在研究区内共设有 30 个样地。

\section{4 数据处理软件}

用 MRT 软件对 MODIS 影像进行投影转 换, 用 PCI、 Envi 和 arcGIS 软件对 MODIS 影 像进行处理、运算、分析和制图, 用 Visual Foxpro 6.0 进行部分程序的编写。

\section{4 理论及研究方法}

根据宋炳显先生的观点, 生态用水量为: 生态用水量=植被蒸散量+土壤贮水量。

流域蒸散量主要基于地表能量平衡原理 估算 ${ }^{8}$ :

$$
L E=R_{n}-G-H
$$

式中, $R_{n}$ 为地表净辐射通量, $W / m^{2}, G$ 为土 壤热通量, $W / \mathrm{m}^{2}, H$ 为显热通量, $W / \mathrm{m}^{2}, L E$ 为潜热通量, $W / m^{2}$ 。

首先估算地表特征参数各分量(归一化植 被指数, 植被盖度, 地表比辐射率, 地表反照 率), 然后得到地表能量平衡各分量(净辐射通 量, 土壤热通量, 显热通量, 潜热通量), 由 此算出瞬时蒸散量, 通过积分运算, 时间尺度 扩大到日蒸散量, 根据包括该月中日子的遥感 结果按所占日数进行了加权求和得到月蒸散 量。具体方法及公式请参见参考文献[8]。

土壤咜水量根据地表含水量指数 SWCI 进行运算 ${ }^{[9]}$ :

$$
S W C I=\frac{b 6-b 7}{b 6+b 7}
$$

式中, b6、b7 分别为 MODIS 数据的第 6、第 7 波段反射率值。该模型从水的吸收对植被和 土壤反射率波谱的综合影响入手, 直接获取其 地表水分含量指标。计算得到的值用野外实测
数据 $(0.5 \mathrm{~m}$ 深度内的土壤含水量) 进行了修正。 同时根据包括该月中日子的遥感结果按所占 日数进行了加权平均得到月土壤咜水量。

由于本文采用地表能量平衡方法和地表 含水量指数法估算流域蒸散量和土壤贮水, 该 方法并不适用于水体，而且所用 MODIS 产品 的分辨率为 $500 \mathrm{~m}$, 该流域水体面积小且河流 窄, 在影像图上基本没有显现, 综上两点, 本 文所研究区域不包括水体。

\section{5 蒸散量结果检验}

利用 $F A O$ 推荐的估算参考作物蒸散的 Penman-Monteith (简称 $P-M$ ) 公式和作物系数对 2012年3月 29 日-10月 6 日每 8 天的日均蒸散量 (共计 23 个时间段)进行了计算, FAO推荐的估 算参考作物蒸散的 $P-M$ 公式为 ${ }^{[10]}$

$$
E T_{0}=\frac{0.408 \Delta\left(R_{n}-G\right)+\gamma \frac{900}{T_{d}+273.16} u_{2}\left(e_{S}-e_{d}\right)}{\Delta+\gamma\left(1+0.34 u_{2}\right)}
$$

式中, $E T_{0}$ 为参考作物蒸散量, $\mathrm{mm} / \mathrm{d} ; R_{n}$ 为作 物表面的净辐射通量, $\mathrm{MJ} /\left(\mathrm{m}^{2} \mathrm{~d}\right) ; G$ 为土壤热 通量, $\mathrm{MJ} /\left(\mathrm{m}^{2} \mathrm{~d}\right) ; \Delta$ 为饱和水汽压斜率, $\mathrm{KPa} /{ }^{\circ} \mathrm{C} ; e_{S}$ 为饱和水汽压, $\mathrm{KPa} ; e_{d}$ 为实际 水汽压, $\mathrm{KPa} ; \gamma$ 为干湿球常数, $\mathrm{KPa} /{ }^{\circ} \mathrm{C}$; $u_{2}$ 为 $2 \mathrm{~m}$ 高度处的风速, $\mathrm{m} / \mathrm{s} ; T_{d}$ 为日均温, ${ }^{\circ} \mathrm{C}$ 。 通过参考作物蒸散量 $E T_{0}$ 和作物系数 $K c$ 可 以确定某种作物的实际蒸散量, 即

$$
E T=K c \cdot E T_{0}
$$

式中, $E T$ 为作物实际蒸散量, $\mathrm{mm} / \mathrm{d}$ 。

参考 FAO56 文件, 作物系数取值如下: 4-5 月份为 0.8, 6-7 月份为 0.95, 8-9 月份为 0.85 。同时对遥感反演的值进行了流域平均, 二者进行对比 (图 2), 平均相对误差为 $16.678 \%$, 在误差允许范围之内。因此, 说明 该遥感方法有一定的可用性。

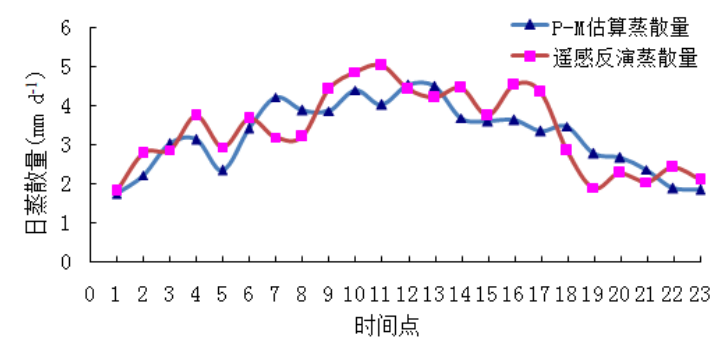

图 2 P-M 估算蒸散量与遥感反演蒸散量对比图 Fig.2. Contrast diagram of P-M evapotranspiration and evapotranspiration of remote sensing retrieval 


\section{6 结果分析}

\section{1 锡林河流域生态用水时空分析}

为便于比较, 采用统一的分类阈值, 制作 了 2000 年、 2007 年、2010-2014 年每年生长 季(4-9 月份)流域总生态用水量(图 3)。由于植 被类型、自然条件的差异, 锡林河流域各地区 生态用水量差异较大, 其空间分布与地表状况 比较吻合, 由上游到中下游逐渐减小, 与植被 覆盖区域、气候条件以及土壤的地带性分布基 本一致, 由东南到西北呈条带状减少趋势。河 流及两侧的低湿地植被、上游地区的草甸草原 生态用水量较大; 林地、耕地生态用水量大于 草地和建设用地; 植被密集地带大于稀疏植被 的生态用水量。
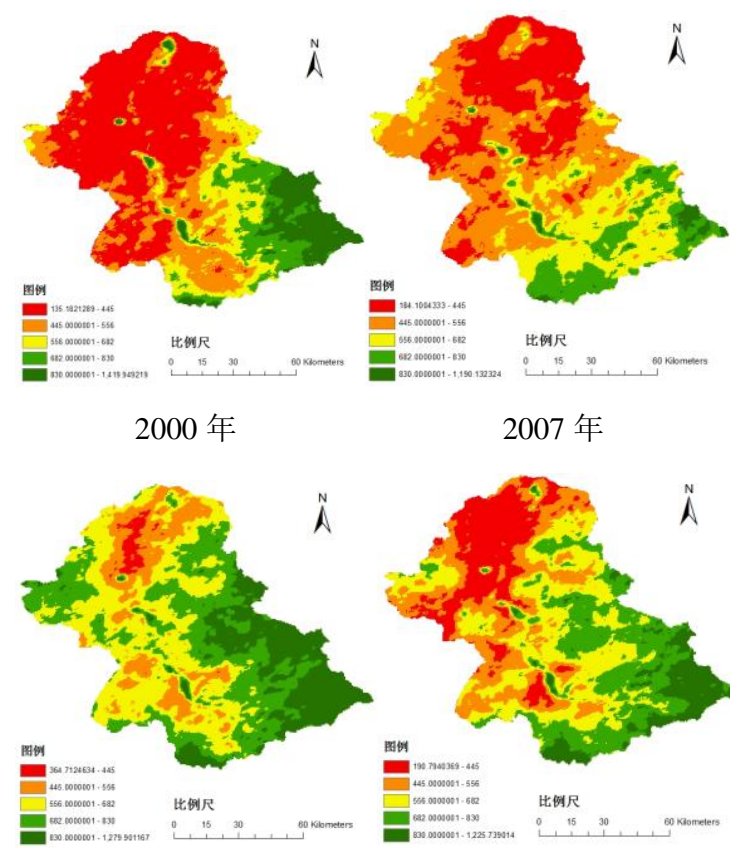

2012 年

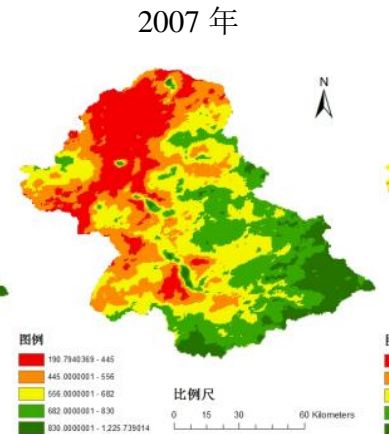

2013 年
图4为生长季生态用水和降水随时间的变 化曲线图。由图可知, 降水充沛年份生长季的 生态用水明显高于降水稀少年份生长季的生 态用水。生态用水量由蒸散量和土壤贮水量组 成, 因此与降水量极为相关。由图3 和图4可知, 降水量大的年份, 生态用水量大, 生态用水量 大的区域所占面积越大，包括流域大部分区 域, 降水量小的年份, 生态用水量也小, 生态 用水量大的区域仅出现在上游地区及河流流 经地段。图5为七年生长季生态用水的直方图, 直方图的峰值及主值区间的变化与降水多塞 的变化相一致, 在降水充沛的年份, 峰值与主 值区间均向横轴右侧移动。锡林河流域日照和 热量充足, 能够满足植被生长的光热条件, 因 此降水量多寡是影响植被长势好坏的主要原 因, 也是限制生态用水大小的主要气候因子。

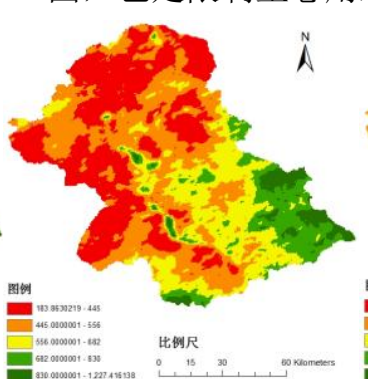

2010 年

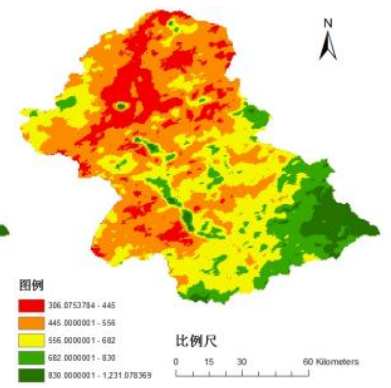

2014 年

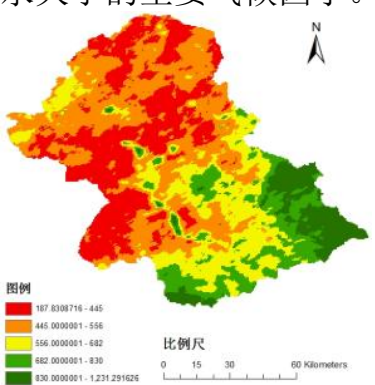

2011 年

图 3 生长季锡林河流域 MODIS 影像反演的月生态用水量 $(\mathrm{mm} / \mathrm{month})$

Fig.3. Ecological water use retrieved from MODIS image of XiLin River Basin in growing season

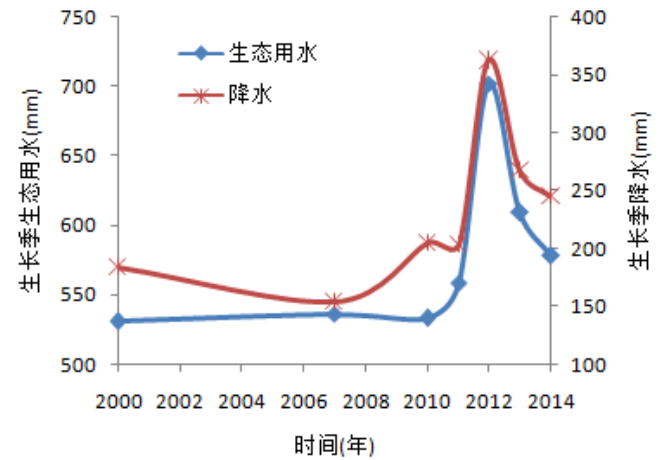

图 4 生长季生态用水和降水随时间的变化曲线图 Fig.4. Ecological water use and precipitation change curve of XiLin River Basin in growing season

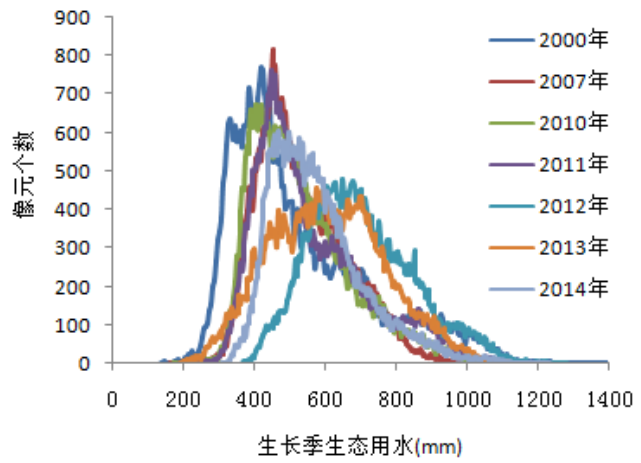

图 5 生长季锡林河流域总生态用水量直方图

Fig.5. Histogram of ecological water use in Xilin River Basin in growing season 


\section{2 不同土地利用类型的生态用水分析}

研究区分为 6 个地类: 草地、耕地、林地、 未利用地、建设用地和水体。如前所述, 本研 究不包括水体。

图 6 为生长季 4-9 月份锡林河流域不同土 地利用类型的生态用水。由图可知, 生态用水 较高的地类为林地和耕地, 其次为未利用地, 草地和建设用地生态用水较低, 基本为林地> 耕地>未利用地>建设用地>草地。林地和耕地 为密集型植被, 林分内土壤咜水量高, 耕地由 于灌溉用水的补给, 土壤咜水量也较高, 此外 这两种地类植被覆盖度高, 叶面积指数大, 植 物蒸腾和土壤蒸发较大; 未利用地主要为流域

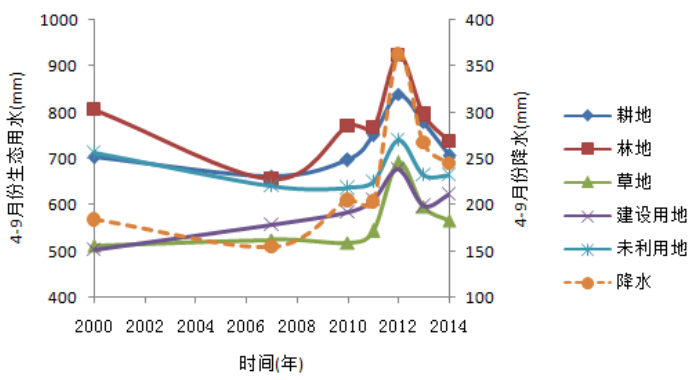

图 6 锡林河流域生长季不同土地利用类型的生态 用水 $(\mathrm{mm})$

Fig.6. Ecological water use of different land use type in Xilin River basin in growing season
两侧的低湿地植被, 由于临近河流, 土壤水分 较充足, 植被蒸散量也较大; 草地的生态用水 较低, 甚至低于建设用地, 主要原因一是城镇 分布有不少的绿化面积, 种植有大量的灌溉树 种和观赏植物, 蒸腾和蒸发较大, 二是整个流 域大部分为草地所覆盖, 可是草地的类型和覆 盖度是不一样的, 虽然上游草地植被覆盖度 高, 蒸散量较大, 土壤水分较充足, 但所占面 积小, 中下游草地植被稀疏, 蒸散量小, 特别 是在降水亏缺的年份, 出现干旱状态, 所以平 均下来草地的生态用水较低, 但在降水充沛的 年份, 由于降水补给充足, 会出现草地的生态 用水与建设用地的生态用水相当的情况。

图7为锡林河流域生长季不同土地利用类 型的月生态用水。在降水充沛的年份, 有充足 的水分对土壤水进行补给, 土壤含水量较高, 同样有充足的水分可供蒸发蒸腾, 蒸散量较 大, 因此各地类生态用水量均较大, 最大值主 要出现在雨量充沛的6-7月份。在降水欠缺的 年份, 土壤含水量低, 也没有充足的水分可供 蒸散, 蒸散量在各个月均相差不大, 因此各地 类生态用水量较小, 变化也较为平缓, 最大值 出现的时间没有规律。
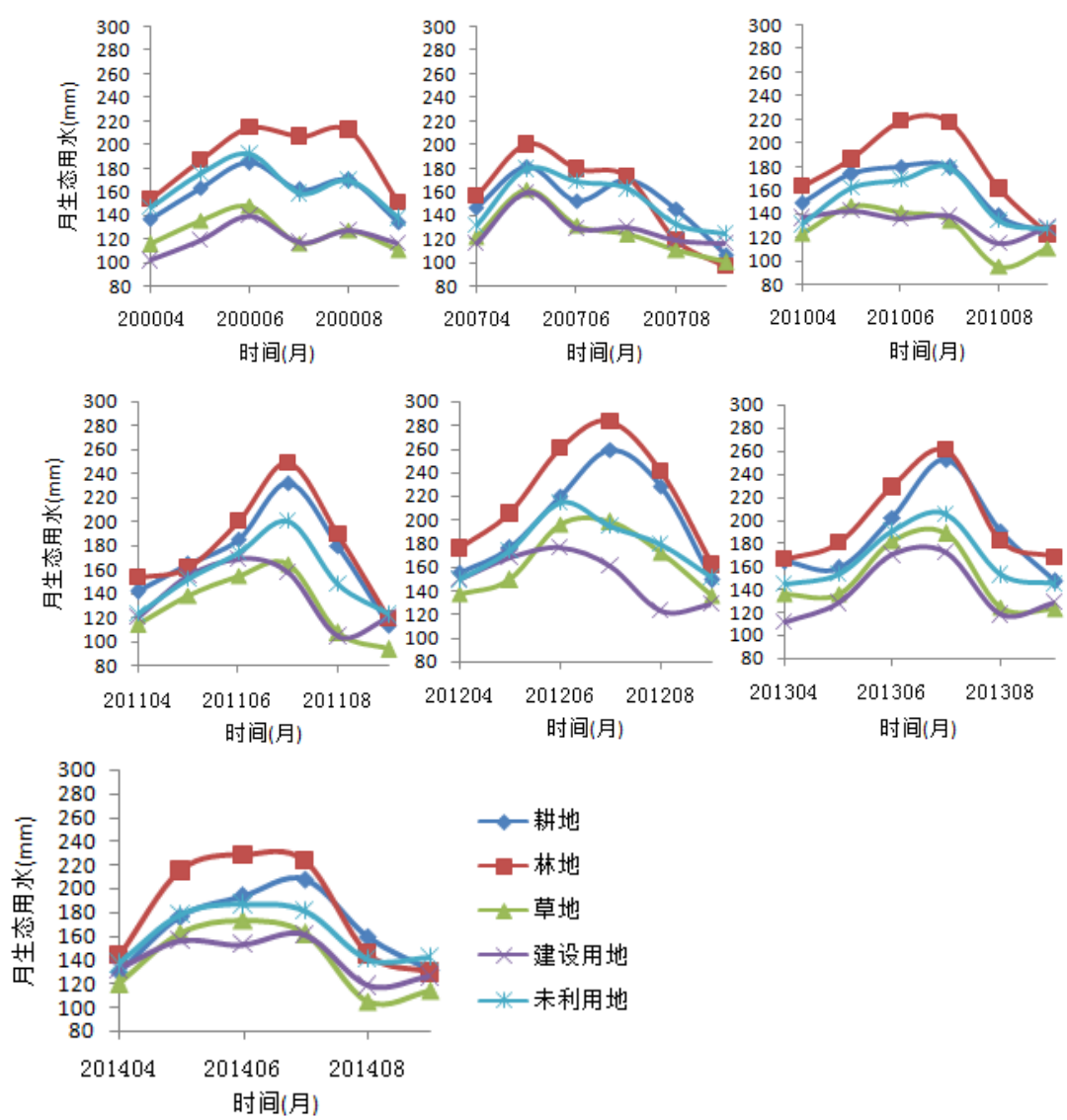

图 7 锡林河流域生长季不同土地利用类型的月生态用水 $(\mathrm{mm})$

Fig.7. Monthly ecological water use of different land use type in Xilin River basin in growing season 


\section{3 锡林河流域生态用水与气象因子的关 系}

图 8 为月生态用水与月降水量散点图, 它 们之间有较好的线性相关性:

月生态用水 $(\mathrm{mm})=0.759 \times$ 月降水 $(\mathrm{mm})+110.3$ $\left(\mathrm{R}^{2}=0.601\right)$

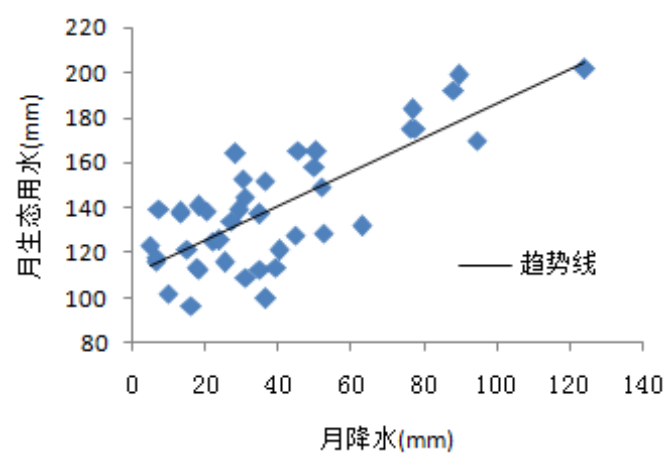

图 8 生态用水与降水散点图

Fig. 8. Scatter diagram of ecological water use and precipitation

七年的月生态用水量与月日均气温、风 速、大气相对湿度、水汽压和月降水量的单因 子相关分析如表 1 所示, 结果表明, 生态用水 量与降水量的相关性最大, 为 $\mathrm{P}<0.1$ 显著正相 关, 其次为水汽压和气温, 均为 $\mathrm{P}<0.5$ 显著正 相关，与风速和大气相对湿度的相关性较小， 均为正相关。由此可知, 水分是影响生态用水 量大小的主要限制因子, 由于气温季节变化明 显, 因此气温也是影响生态用水量的重要因 子。

\section{表 1 4-9 月份锡林河流域月生态用水量与气象} 因子之间相关关系

Table 1. Correlation between monthly ecological water use and meteorological factors of XiLin River Basin from Apr. to Sept.

\begin{tabular}{cccccc}
\hline 指标 & 气温 & 风速 & $\begin{array}{c}\text { 大气相 } \\
\text { 对湿度 }\end{array}$ & $\begin{array}{c}\text { 水汽 } \\
\text { 压 }\end{array}$ & $\begin{array}{c}\text { 降水 } \\
\text { 量 }\end{array}$ \\
\hline 相关系数 & 0.336 & 0.082 & 0.253 & 0.380 & 0.776 \\
\hline
\end{tabular}

\section{7 结论}

本研究选择锡林河流域为研究区, 对 MODIS影像进行处理及运算, 运用遥感方法 反演出2000年、2007年、2010-2014年每年4-9 月份生长季的生态用水量。经过分析, 结论如 下:

流域生态用水量空间分布与地表状况比 较吻合, 生态用水量基本均为由上游到中下游 呈条带状减少的趋势。河流及两侧的低湿地植 被、上游地区的草甸草原生态用水量较大; 林 地、耕地生态用水量大于草地和建设用地; 植 被密集地带大于稀疏植被的生态用水量。年际
变化与降水量极为相关, 降水量大的年份, 生 态用水量大, 生态用水量大的区域所占面积越 大，包括流域大部分区域，反之亦然。

生态用水较高的地类为林地和耕地, 其次 为未利用地, 草地和建设用地生态用水较低, 基本为林地 $>$ 耕地 $>$ 未利用地 $>$ 建设用地 $>$ 草 地。

在降水充沛的年份, 生态用水最大值主要 出现在雨量充沛的6-7月份, 在降水欠缺的年 份, 最大值出现的时间没有规律。

将月生态用水量与月气象数据进行了单 因子相关分析, 表明降水是影响生态用水量大 小的主要限制因子, 相关系数为 0.776 , 它们 之间具有较好的线性相关。

\section{致谢}

国家自然科学基金项目(41661009); 内蒙古自治区 自然科学基金（2017MS0408）；内蒙古自治区高 等学校科研项目 (NJZY17047)

\section{参考文献}

[1] P. Hao and L. Zhen Qing, Evaluation of grassland ecosystem services in Xilin River basin, ACTA PRATACULTURAE SINICA. 16(4) (2007) 107-115.

彭皓, 李镇清,锡林河流域天然草地生态系统服 务价值评价,草业学报.16(4)(2007)107-115.

[2] W. Yu Juan, W. Shu Dong, Y. Sheng Tian, et al, Dynamic Simulation of Vegetation Eco-water of the Yellow River Basin, JOURNAL OF NATURAL RESOURCES. 29(3) (2014) 431440.

王玉娟,王树东,杨胜天, 等,黄河流域植被生态 用水过程动态模拟,自然资源学报. 29(3) (2014) 431-440.

[3] H. Ge Sheng, On Improvement of Ensuring System concerning Eco-environmental WaterUse in China, Hebei Law Science. 34(7) (2016) 16-29.

胡德胜,论我国生态用水保障制度的完善,河北 法学. 34(7)(2016)16-29.

[4] P. Xingyao, L. Honglu, L. Fahu, et al, Ecological water requirement of irrigated region in Tongzhou District of Beijing based on GIS technique, Transactions of the Chinese Society of Agricultural Engineering. 23(2) (2007) 42-47. 潘兴瑶,刘洪禄,李法虎,等,基于 GIS 技术的北京 通州区灌区生态需水研究, 农业工程学 报.23(2)(2007) 42-47.

[5] C. Chao, P. Xuebiao, Z. Lizhen, et al, Impact of climate change on cotton production and water consumption in Shiyang River Basin, Transactions of the Chinese Society of Agricultural Engineering. 27(1) (2011) 57-65. 陈超,潘学标,张立祯,等,气候变化对石羊河流 域棉花生产和耗水的影响, 农业工程学 报.27(1)(2011) 57-65. 
[6] S. Bing Yu and Y. Jie, Discussion on ecological use of water research, Journal Of Natural Resources. 18(5) (2003) 617 -625

宋炳显,杨劼,关于生态用水研究的讨论,自然资 源学报.18(5)(2003)617-625.

[7] G. Xiao He, H. Chun Yang, P. Yao Zhong, et al, Optimizing management on degraded grassland in Xilin River Basin based on ecological risk assessment, Chinese Journal of Applied Ecology. 18(5) (2007) 968-976.

顾晓鹤,何春阳,潘耀忠, 等,.基于生态风险评估 的锡林河流域退化草地优化管理,应用生态学 报.18(5) (2007)968-976.

[8] Y. Hong Bo, B. Yu Hai, L. He Ping, et al, Remote Sensing Retrieval of Evapotranspiration in Xilin River Watershed, Research of Soil and Water Conservation. 21(1) (2014) 224-228.

于红博,包玉海,李和平,等,锡林河流域蒸散量 遥感反演,水土保持研究.21(1)(2014)224-228.

[9] D. Xiao, W. Shi Xin, Z. Yi, et al, A Digital Image Watermarking Algorithm Based on Quadtree and Error Correcting Code, Geomatics and Information Science of Wuhan University. 32(3) (2007) 205-207, 211.

杜晓,王世新,周艺,等,一种新的基于 MODIS 的 地表含水量模型构造与验证,武汉大学学报(信 息科学版).32(3)(2007)205-207,211.

[10] Y. Hong Bo, Evapotranspiration Estimated by a Scaling Model in the Ordos Plateau, China, PhD thesis, Huhhot: Inner Mongolia University, (2009), pp.26-28.

于红博, 黄土丘陵沟壑区植物蒸腾和植被蒸散 估算尺度转换模型研究, 内蒙古大学博士学位 论文, 内蒙古大学,2009,26-28. 